\title{
Literatura e medicina: o território partilhado
}

\author{
Literature and medicine: the shared territory
}

Moacyr Scliar 1

\footnotetext{
1 Departamento de Medicina Preventiva, Fundação Faculdade Federal de Ciências Médicas de Porto Alegre. Rua Sarmento Leite 245, Porto Al egre, RS 90050-170, Brasil.
}

Abstract The text De Profundis: Valsa Lenta (De Profundis: Slow Waltz), by Portuguese author José Cardoso Pires, describing the aphasia he experienced after a stroke, was used as a starting point to study the different approaches writers and physician have regarding the disease. The differences in form and content of texts describing the disease in literature and medicine fit in the conflict between the two cultures, as described by C.P. Snow, and are typical of theincreasing specialization. The addition of literary texts in training programs for doctors and health professi onals may help overcome this gap, making it easi er to understand the disease in its broader dimension and collaborating to improve the relationship between patients and professionals. Key words Literature; Medicine; Medicine in Literature; Medical Education

Resumo Partindo do texto do escritor portuguêsJ oséCardoso Pires, "De Profundis: Valsa Lenta", em que o autor descreve a afasia pela qual passou em conseqüência de acidente vascular cerebral, são fei tas consi derações sobre o enfoque da doença por escritores e por médicos. As diferenças apontadas, em termos da forma e do conteúdo dos textos que, na literatura e na medicina, descrevem a doença, enquadram-se no conflito entre as duas culturas, tal como descrito por C. P. Snow, sendo característico da crescente especiali zação. A inclusão de textos literários no treinamento de médicos e de profissi onais da saúde pode ajudar a superar esse hiato, facilitando o entendimento da doença em sua dimensão mais ampla e contribuindo para um mel hor relacionamento profissional-paciente.

Palavras-chave Literatura; Medicina; Medicina na Literatura; Educação Médica 
Numa conferência na Universidade de Cambridge, em 1959, Charles Peirce Snow Iançou um conceito que, não sendo de todo original, teria, contudo, vasta repercussão. Trata-se do "conceito das duasculturas", que pode ser assim sumarizado: entre a cultura científica e a cultura literária existe um "abismo de mútua incompreensão": os cientistas não se interessam por literatura, os literatos não entendem princípios científicos básicos como a segunda lei da termodinâmica (Snow, 1982:5). O conferencista tinha credenciais para fazer tal observação; físico por formação, ensinava em Cambridge, mas era também novelista e ensaísta de certa reputação.

Nas quatro décadas que se passaram a crescente especialização só fez aumentar o hiato descrito por Snow - e as preocupações em superá-lo. O objetivo do presente artigo é examinar um particular caso no relacionamento intercultural, qual seja, a relação entre medicina e literatura. Trata-se de uma situação diferente daquela examinada por Snow. Se concebemos a ciência como uma avaliação invariável e sempre preditiva do universo material, a medicina dificilmente se enquadrará neste conceito. Mas, como dizia Cabanis, a medicina moderna busca, através da observação cuidadosa, da classificação racional e do método experimental, adquirir uma relativa, provável e prática certeza (Staum, 1980). Ou seja: a medicina se vê como ciência. Fala a linguagem da ciência e portanto se situa no âmbito da cultura científica. De outra parte, a doença e a prática médica são temas freqüentes na obra de poetas, romancistas, ensaistas. Textos clássicos o exemplificam: A Morte de Ivan Illich, de Leon Tolstoi, fala do penoso confronto com o término da existência e a problemática relação médico-paciente nesta situação; A Montanha Mágica, de Thomas Mann, tem como cenário um sanatório de tuberculosos; O Al ienista, de Machado de Assis, é uma sátira à psiquiatria autoritária do século dezenove.

A abordagem que escritores fazem da enfermidade é obviamente diferente daquela usada habitualmente pela medicina. Tomemos o caso daquele comum texto médico, a anamnese. O termo vem do grego; significa o contrário da perda de memória (amnésia) ou seja, a recordação. É o ato pelo qual o paciente recorda, para o médico, a história de seu padecimento ou do agravo à sua saúde. A partir daí se inicia o processo de diagnóstico e tratamento.

$O$ registro da enfermidade não se restringe, obviamente, à anamnese. Pode ser feito de outras maneiras, inclusive através de um texto literário, como aconteceu com muitos poetas e escritores enfermos. A comparação entre tal tipo de texto e a anamnese ilustra as diferenças entre "as duas culturas", mas também evidencia a existência de um território comum, partiIhado, que pode se revelar um fértil campo de experiência humana e científica.

Em 1995 o escritor português José Cardoso Pires teve um acidente vascular cerebral. Foi hospitalizado, e recuperou-se (um segundo acidente vascular cerebral acarretaria sua morte, em 1998). Desse duro transe resultou um curto, mas transcendente texto (Cardoso Pires, 1997), revelador dos temores e da ansiedade pelas quais passa um paciente nesta situação limite. Texto este que conta com dois complementos: um prefácio, elaborado pelo neurologista que tratou de Cardoso Pires, o Prof. João L. Antunes, e um posfácio do próprio escritor.

O agravo se manifestou de forma relativamente súbita. Sentado à mesa do pequeno almoço, com a esposa e um casal amigo, José Cardoso Pires deu-se conta de que algo diferente, e assustador, estava ocorrendo com ele: "Sintomemal, nunca me senti assim." Voltou-se para a esposa, e perguntou-Ihe como se chamava.

“Pausa. 'Eu? Edite.' Nova pausa. 'E tu?'

'Parecequeé Cardoso Pires', respondi."

Nestas duas linhas está expressa toda o drama de quem atravessa a imprecisa linha entre saúde e doença. O escritor faz à esposa uma pergunta insólita, absurda mesmo. Ela não responde de imediato. Há uma pausa. Pausa tensa, como é fácil de imaginar. Nos poucos segundos que pode ter durado tal pausa, muitas dúvidas devem ter passado pela mente dela: estará ele brincando ou estará perturbado? Como responder à brincadeira, como enfrentar a perturbação? Ela opta por responder de forma direta. Depois da curta interrogação, que expressa ainda a perplexidade ("Eu?") diz o seu nome. E aí nova pausa, que corresponde ao dilema: o que fazer agora? A pergunta seguinte tem caráter investigativo: visa a descobrir se há uma perturbação da memória, e até que ponto vai tal perturbação. A resposta confirma a suspeita; primeiro, porque dá prosseguimento ao diálogo absurdo - o escritor poderia ter dito algo como "que história é essa de perguntar meu nome, tu sabes meu nome"; segundo, porque ele está claramente inseguro quanto a algo que é fundamental para os seres humanos.

Há mais, porém. Depois desta introdução, curta mas importante - o autor coloca-a como o capítulo inicial - Cardoso Pires vai além, e explora o duplo sentido de sua resposta. A frase "Parece que é Cardoso Pires" pode ser entendida como "Parece que meu nome é Cardoso Pires", mas também como "Parece que ele (o nome ou o homem, M. S.) éo Cardoso Pires". A diferença é crucial. A segunda acepção - e esta é, 
para José Cardoso Pires, a verdadeira - implica um processo de despersonalização, de perda de identidade. Como observa o próprio Cardoso Pires, no texto, é estranho que não tenha usado o prenome, "o mais significativo entre marido emulher eo único que nos era natural".

Fato ominoso. O nome de uma pessoa tem um transcendente significado psicológico e cultural. Para os Inuit do Canadá, o ser humano é o resultado de uma associação entre corpo, alma e nome - este transmitido, num processo análogo à reincarnação, por alguma outra pessoa ao recém-nascido, estabelecendo-se assim “uma cadeia homonímica que protege a criatura e lhe transmite as capacidades dos homônimos". Para os Samo, de Burkina-Fasso, há uma concepção semel hante: a pessoa é composta de substâncias corporais (carne, sangue, esperma), de uma essência espiritual e de seu nome. Que é um indicador de status: os escravos dos romanos não tinham direito a nome (Zonabend, 1994). Assim, “...o nome próprio indi vidualiza o sujeito, identifica-o e o personaliza. O conjunto de signos queforma o nome próprio, além de servir de marca formal designativa do indivíduo para os outros, para a sociedade, constitui-se como um referencial único para o sujeito: el e o vivecomo sendo ele mesmo." (Martins, 1991:43).

Nos dias que se seguiram, várias vezes Cardoso Pires foi chamado pelo nome. Mas a sensação de estranheza persistia: "que nome tão feio, considerava eu" (p. 41). Com o diagnóstico de grave acidente vascular cerebral isquêmico é internado (contra a vontade: "era ainda um último resto de mim que protestava", p. 28). Afásico, já não tem controle sobre seu universo vocabular: "era desvairada a nomenclatura que el e atribuía aos objetos"(p. 33). Mais que isto, “...a desmemória não só o isol ou da realidade objetiva como o destituiu, pode dizer-se, desentimentos." (p. 38). E a pergunta se impõe, sombria: como escrever, nesta situação? Ou, como o próprio Cardoso Pires a formula: “O querestaria de mim no homem que ficou para ali estendido à espera de coisa nenhuma?" (p. 31).

De alguma maneira, no entanto, ele continua escritor. Continua ficcionista. Se já não pode colocar no papel uma narrativa, ele a vive, e nisto é, paradoxalmente auxiliado pela própria despersonalização que acompanha o quadro. Para este ficcionista, o outro Cardoso Pires, o doente, é uma espécie de "doppelgänger". A experiência do "duplo", ou autoscopia, é conhecida desde Aristóteles. Pode ocorrer com pessoas normais, mas é mais comum entre pacientes delirantes ou portadores de lesão cerebral. Fenômenos autoscópicos freqüentemente aparecem na literatura, sempre antecipando uma tragédia, como o exempli- ficam textos de Dostoievsky, Kafka, Maupassant e Poe (Reed, 1987). Particularmente interessante, porque, pelo humor, foge em parte a esta regra, é o texto "Borges e eu", de Jorge Luis Borges:

"Ao outro, a Borges, é a quem sucedem as coisas. Eu caminho por Buenos Aires e me demoro, já mecanicamente, a mirar o arco de um saguão e uma porta; de Borges tenho notícias pelo correio e vejo seu nome em um trabal ho de professores ou em um dicionário biográfico. Gosto dos relógios de areia, dos mapas, da tipografia do século XVIII, das etimologias, do gosto do café e da prosa de Stevenson; o outro comparte estas preferências, mas de um modo vaidoso que as converte em atri butos de um ator. Seria exagerado dizer que nossa relação éhostil; eu vivo, eu me deixo viver para que Borges possa tramar sua literatura eessa literatura mejustifica." (Borges, 1960:69-70).

Considerando que o Outro "nada mais era que uma sombra saída de algures de mim ea desl ocar-se por si só não se sabe em que direção, nem com que o objetivo"(p. 41), Cardoso Pires pergunta-se: "como foi que desse apagamento consegui reter al guma luzinha a brilhar atéagora?" (p.41). A resposta é dada pelo texto de Borges e pelo próprio DeProfundis: era o escritor que, em Cardoso Pires, conservava esta imagem fugidia. E a conservava para depois - se possível - transformá-la em literatura. Difícil, penosa, tarefa. Em alguns momentos, Cardoso Pires perguntou-se se não estava a caminhar para a loucura. Isto acontecia, por exemplo, quando não conseguia decifrar o letreiro sobre a porta do banheiro, e que dizia Banhos. Mas o letreiro, assim como o Outro, acabam funcionando como um estimulante desafio: "Ao enfrentar aquele letrei ro como uma provocação da lei tura e da escrita, era o ex-autor de livros que estremecia na cegueira em que tinha mergulhado eque tirava, do fundo da sua razão perdida, o esboço deuma interrogação à loucura." (p. 45).

Há mais estímulos. Ao lado do Outro ficcional, fascinante e assustador, há Outros reais: os dois companheiros de quarto, a família, os médicos, o pessoal de enfermagem, pessoas que se esforçam por mantê-lo conectado à realidade. O que provavelmente ajudou na recuperação, aliás rápida, de José Cardoso Pires. E, tão logo recuperado, o escritor tratou de colocar no papel o relato de sua experiência. Fê-lo sob a forma de um resumido, enxuto, relato não-ficcional, de uma "Memória", como ele o chama, e que se caracteriza pelo objetividade. Tal como menciona no pósfácio, procurou evitar: a) as explicações médicas do ocorrido e b) "as seduções que a ficção tende a extrair da natureza dum tema carregado de efei tos e dramatismo" 
(p. 68). Ou seja: o ficcionista, que pode ter sido o observador do Outro, agora é dispensado. Mesmo assim, o texto é rigorosamente literário.

O que o torna ainda mais importante. Como observa o Prof. Antunes na introdução (redigida sob forma de uma carta ao escritor): "Devo dizer-Ihe que é escassa a produção literária sobrea doença vascular cerebral. A razão ési mples: éque el a seca a fonte de onde brota o pensamento ou perturba o rio por onde la se escoa e assi m édi fícil explicar aos outros como se dissolvea memória, se suspendea fala, se embota a sensi bilidade, secontém o gesto. E muitas vezesa agressão, como aquela queo assaltou, deixa cicatriz definitva, que impede o retorno ao mundo dos real mente vivos. É por isso queseu testemunho ésingular." (p. 9).

Singularidade que fica mais evidente quando comparada à anamnese médica. Esta não figura no livro, mas textos semelhantes diriam: “Paciente internado de urgência por distúrbio da palavra eda memória resultante de provável acidente vascular cerebral. Refere a esposa que, pela manhã, o paciente subitamente perguntou-I he como se chamava. À ocasi ão, mostrou dúvi da sobre o seu próprio nome..." A anamnese é um texto compreensivel mente abreviado, redigido em linguagem técnica, portanto neutra, seguindo um roteiro pré-estabelecido cujo objetivo básico é conduzir a um diagnóstico. Ocasionalmente, as palavras do paciente podem ser transcritas, mas isto acontece quando são demasiado chamativas ou bizarras - e aí estarão acompanhadas do vocábulo latino sic (assim, assim mesmo). A redação será correta, mas jamais literária; não se trata de uma "obra aberta", mas sim de um processo de comunicação auto-explicativo. O paciente é que deve funcionar como um texto, conceito que foi lançado pelo famoso clínico William Osler. Num

\section{Referências}

BORGES, J. L., 1960. El Hacedor. Buenos Aires: Emecé. BRODY, H., 1988. Stories of Sickness. New Haven: Yale University Press.

CARDOSO PIRES, J., 1997. De Profundis, Valsa Lenta. Lisboa: Publicações Dom Quixote.

COLES, R., 1989. The Call of Stories: Teaching and the Moral Imagination. Boston: Houghton Miflin.

KLEINM AN, A., 1988. The IIIness Narratives: Suffering, Healing and the Human Condition. New York: Basic Books.

MARTINS, F., 1991. O NomePróprio: Da Gênese do Eu ao Reconhecimento do Outro. Brasília: Editora da Universidade de Brasília.

OSLER, W., 1904. On the need of a radical reform in our methods of teaching medical students. Medical News, 82:49-53. seminal ensaio publicado no início deste sécuIo, Osler sugeriu aos professores de medicina que afastassem os alunos dos livros e os levassem ao leito do enfermo (Osler, 1904). Naquele momento, tal posição era compreensível e necessária; tratava-se de evitar uma predominância da teoria sobre a prática, uma cultura médica livresca. Mas o pêndulo se inclinou demasiadamente na direção oposta, configurando o hiato entre culturas de que fala Snow. Por exemplo: ao formato clássico da anamnese foi proposta uma modificação, conhecida como prontuário orientado a problemas (Weed, 1968), que organiza o relato médico e os documentos a ele anexos de forma racional mas inevitavelmente acentua a distância a diferença entre a anamnese convencional e textos como o de José Cardoso Pires. A questão que se coloca é: como superar tal hiato na prática da medicina e no ensino médico? Nos últimos anos vários autores (Brody, 1988; Kleinman, 1988; Coles, 1989) propuseram a inclusão de textos literários no currículo médico, dentro das chamadas humanidades médicas, área que inclui história da medicina, ética médica, antropologia e sociologia médicas, comunicação médica. Kathryn M. Hunter, que coordena esta área na Northwestern University Medical School (USA), sintetiza as razões para a introdução dos textos literários no currículo médico (Hunter, 1991), demonstrando que a grande literatura alarga o campo de visão dos profissionais, situando a doença no contexto maior da existência e dos valores humanos, revelando de forma privilegiada - esclarecedora mas sempre emocionante - os bastidores da doença. Pode assim colaborar para diminuir a distância entre as duas culturas, e transformá-las em uma cultura só, que é a cultura do ser humano em sua totalidade.
REED, G. F., 1987. Doppelgänger. In: The Oxford Companion to the Mind (R. L. Gregory, ed.), pp. 200201, Oxford: Oxford University Press.

SNOW, C. P., 1982. The Two Cultures and a Second Look. London: Cambridge University Press.

STAUM, M. S., 1980. Cabanis: Enlightment and Medical Philosophy in the French Revolution. Princeton: Princeton University Press.

WEED, L. I., 1968. Medical records that guide and teach. New England Journal of Medicine, 278:593600

ZONABEND, F., 1994. Temps et contretemps. In: Nom, Prénom: La Règle et lejeu (A. Chalanset \& C. Danziger, org.), pp. 96-97, Paris: Éditions Autrement. 